ANÍBAL ALEXANDRE LIMA DINIZ

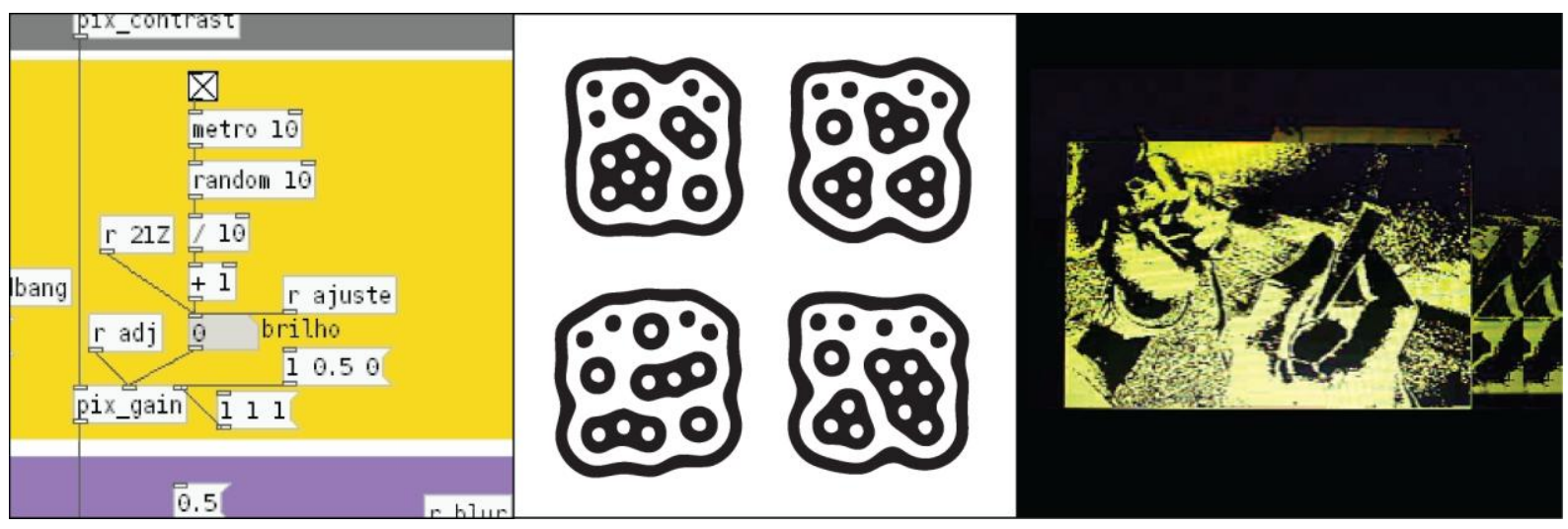

Narrativas Caóticas

Brasília, 2011 
ANÍBAL ALEXANDRE LIMA DINIZ

\section{Narrativas Caóticas}

Trabalho de conclusão do curso de Artes Plásticas, habilitação em Bacharelado, do departamento de Artes Visuais do Institudo de Artes Da Universidade de Brasília

Orientadora: Profa. Dra. Maria Beatriz de Medeiros 
A vida não tem fórmulas. São os intelectuais que têm uma fórmula para impor à vida.

Jiddu Krishnamurti 
Sumário

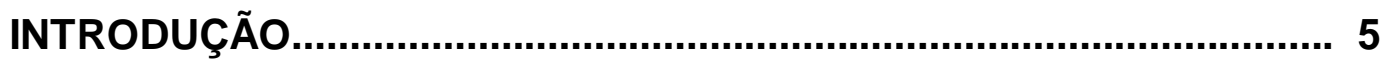

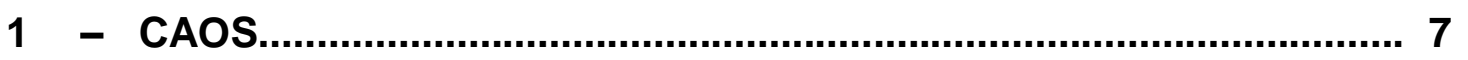

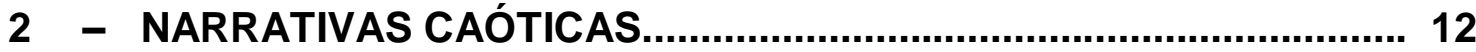

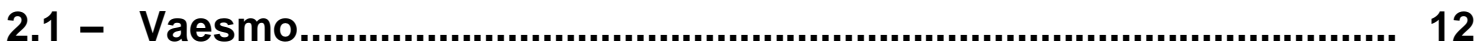

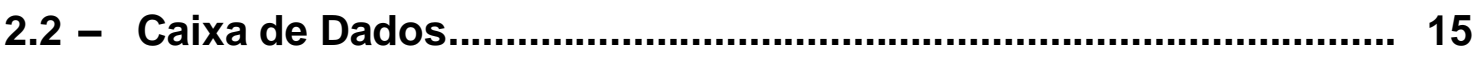

3 - CONSIDERAÇÕES FINAIS............................................................ 17

4 - REFERÊNCIAS BIBLIOGRÁFICAS............................................... 18

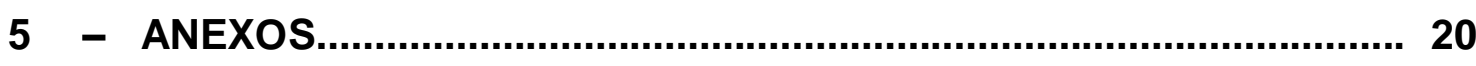




\section{Introdução}

A presente monografia baseou-se em algumas relações interdisciplinares entre arte, ciência e tecnologia, e relata a busca da criação de uma poética envolvendo arte multimídia e Teoria do Caos, calcada na importância de explorar espaços híbridos das artes contemporâneas. Como resultado prévio dessas idéias apresentamos a obra Vaesmo.

Vaesmo é uma experiência audiovisual interativa, possibilitada pela captação e rastreamento de marcadores em movimento através de uma câmera de vídeo. Foi realizada em parceria com Victor Hugo Soares Valentim, estudante da composição do curso de música da Universidade de Brasília.

Esta obra foi feita dentro das possibilidades oferecidas pela linguagem de programação do software Pure Data. Criamos um programa que batizamos de VijhoDrão, em referência ao termo VJ ou Visual Jóquei, meio de expressão ligado a performance de vídeo em tempo real e que tem se tornado muito popular na atualidade em eventos musicais, principalmente de música eletrônica. Também foi utilizado o programa de computador reacTIVison, que possibilitou o reconhecimento dos dados enviados pela câmera de vídeo. Ambos os programas são livres para serem usados, copiados, estudados e redistribuídos sem nenhuma restrição.

Uma das motivações para a criação da obra veio das várias experiências realizadas por artistas que buscam a relação entre som e imagem. Podemos elencar Schoenberg e Kandinsky, Stravinsky e Picasso, John Cage e o grupo Fluxus, e mais atualmente como Brian Kane, desenvolvedor do primeiro programa de VJ. No Brasil podemos citar Villa-Lobos e os modernistas e ainda 
Jorge Antunes com sua obra Miró Escuchó Miró classificada pelo seu autor como música cromofônica ${ }^{1}$, Alexandre Rangel (VJ Xorume).

Outra motivação veio do desejo de criar um programa próprio que atendesse melhor as nossas tendências criativas e expressivas, permitindo, dentro das nossas limitações quanto a capacidade técnica de programação, uma expressão mais livre dos programas existentes no mercado. Também a possibilidade de distribuição para a comunidade artística e democratização dos meios de produção cultural.

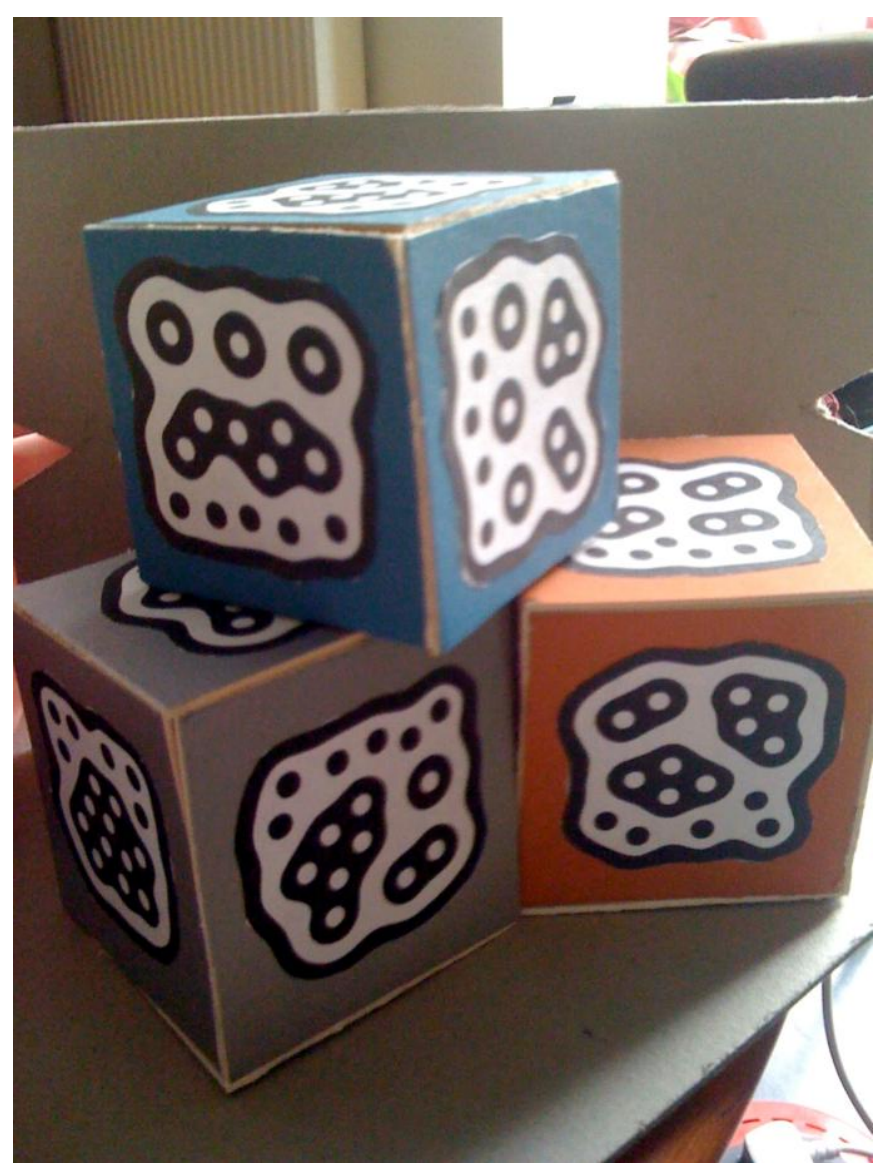

Fiducials, marcadores que são reconhecidos pelo programa e usados para a interação.

\footnotetext{
${ }^{1}$ Música que se utiliza da correspondência entre som e cores.
} 


\section{I.Caos}

A observação de fenômenos naturais nos mostra a todo instante realidades imprevisíveis. As descobertas feitas pela Teoria do $\mathrm{Caos}^{2}$ mostraram que a calculabilidade da matéria e a modelagem matemática e computacional da realidade ainda são muito limitadas devido ao fato da matéria ser muito complexa.

Muitos pesquisadores, dos mais diversos campos de estudo, têm constatado em seus experimentos com os Sistemas Dinâmicos não Lineares que: quanto mais complexo é um sistema maior a probabilidade de pequenos fatores alterarem os resultados enormemente. Exemplo muito comum pode ser o da nossa incapacidade de prever condições meteorológicas para daqui algumas semanas.

A utilização de modelos que se assemelham a fenômenos com que nos deparamos em nosso dia a dia para criar simulações que denotem esses comportamentos que chamamos de aleatórios servem para nos aproximarmos da compreensão a respeito o fator caótico presente no mundo.

Observa-se, nas poéticas contemporâneas, o uso da modelagem randômica ${ }^{3}$ em computador para se abordar temas relacionados à Teoria do

\footnotetext{
${ }^{2}$ Teoria do Caos, para a Física e a Matemática, é a hipótese que explica o funcionamento de sistemas complexos e dinâmicos. Em sistemas dinâmicos complexos, determinados resultados podem ser "instáveis" no que diz respeito à evolução temporal como função de seus parâmetros e variáveis.

${ }^{3}$ É a utilização de padrões matemáticos na análise e interpretação de dados dos eventos natureza que são supostamente indeterminados, como previsões meteorológicas, crescimento de populações, curso de rios, formação de relevos entre outros.
} 
Caos: aleatoriedade ou não previsibilidade da matéria. A Matemática Fractal ${ }^{4} \mathrm{e}$ a teoria dos Atratores Caóticos $^{5}$, por exemplo, tem servido de forma significativa para a compreensão da realidade natural e para modelagem virtual da realidade, para simulação, para síntese sonora ou imagética em tempo real ou mesmo para especulações na área de inteligência artificial.

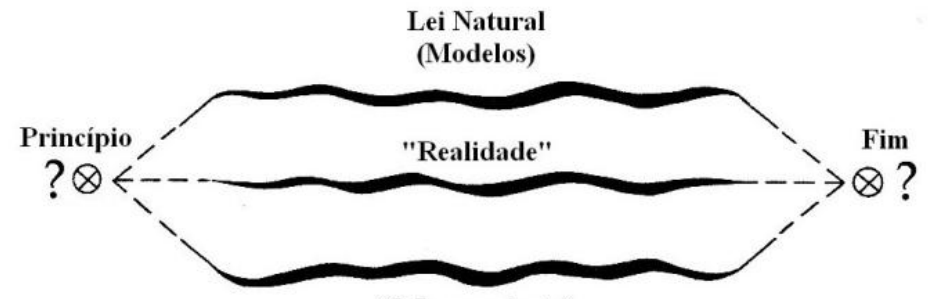

(O Inconsciente)

Caos

À medida que o tempo avança para a direita, três camadas de história jorram de um ponto, $\mathrm{O}$ Princípio, e

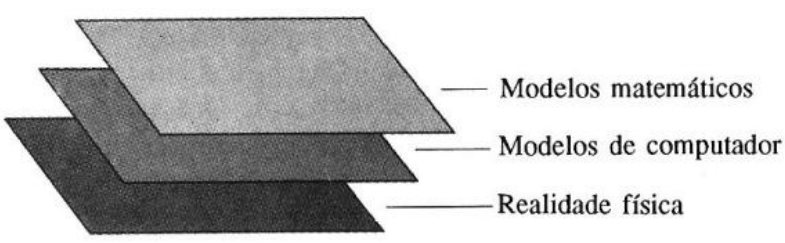
colapsam novamente num

Quando estamos observando sistemas randômicos ${ }^{6}$, percebemos que eles são dotados de cinética. Tendemos a perceber a seqüência dos eventos como aleatórias, isso se dá pelo fato dos sistemas randômicos aparentemente quebrarem com nossos padrões rítmicos convencionais. Basta pensarmos em quando arremessamos um dado de seis faces, por exemplo, o som deste a se chocar várias vezes com a superfície na qual foi arremessado apresenta sempre uma quebra rítmica e o resultado numérico deste evento nunca podemos prever com exatidão. Traz a hipótese de que esta propriedade natural se assemelha uma consciência criativa, intuitiva, ou talvez seja uma ordem,

\footnotetext{
${ }^{4}$ (do latim fractus, fração, quebrado) são figuras da geometria não-Euclidiana. A matemática fractal descreve muitas situações que não podem ser explicadas facilmente pela geometria clássica, e foram aplicadas em ciência, tecnologia e arte gerada por computador.

${ }^{5}$ Modelos estatísticos para o comportamento caótico: quando num evento os resultados estatísticos apresentam regularidade, desta forma não podendo ser classificados como randômicos, apresentando "probabilidade viciada" - como num jogo de dados viciados, por exemplo - pode se inferir a presença de um atrator caótico..

${ }^{6}$ Sistemas nos quais os resultados de um evento são aleatórios, no caso desses sistemas especificamente a aleatoriedade não é infinita, a gama de variáveis são limitadas num sistema fechado, por exemplo, como no sorteio de números num bingo.
} 
essência ou lei universal que ainda não reconhecemos por fugir aos nossos padrões cognitivos. Uma outra questão é a da possibilidade de nos relacionarmos com esses fenômenos aparentemente ilógicos de uma forma não somente intuitiva, mas alcançarmos uma compreensão lógico-racional.

Esse tipo de conhecimento depende da atenção as dinâmicas caóticas, porém isso não quer dizer que todos esses aspectos são necessariamente relativos, e que não podemos fazer escolhas em função de alguma previsibilidade. Uma outra questão é a de que as escolhas podem ser, ao mesmo tempo, múltiplas e também passíveis de complexidade com a possibilidade do imprevisível também influenciá-las.

Quando assumimos o Caos como podendo ser uma consciência criativa poderíamos, junto a isto, imaginá-la, como dotada de escolha, dar forma, ou mesmo de fazer existir. Sua mutabilidade ocorre num tempo diferente, talvez pelos seus mecanismos de memória. Na década de 80 , o biólogo inglês Rupert Sheldrake, elaborou uma teoria sobre a Ressonância Mórfica ${ }^{7}$ e a Causalidade Formativa. Dizia que existe um princípio diretor, ainda não reconhecido pela Física e nem pela Química, que ordena toda e qualquer organização, de todo e qualquer sistema material. Exemplo: a organização dos elementos físicoquímicos em átomos, moléculas, tecidos, órgãos etc. Serem estruturas que formam de uma maneiras tão específicas e estáveis. Ou mesmo entre milhares de possibilidades de combinações de DNA, apenas uma determinada organização se dá, e de forma tão característica. Rupert Sheldrake se ocupa do problema da morfogenia, ou seja, como e porque certos elementos se agregam para dar origem a sistemas específicos e com uma forma característica, como por exemplo, um coração humano. Esse princípio diretor é chamado por Sheldrake de Campo Morfogenético.

Sheldrake afirma que, entre todo e qualquer campo morfogenético semelhante, ou seja, entre aqueles que orientam sistemas materiais semelhantes, ocorre um fenômeno pelo qual os campos se comunicam. Quanto mais indivíduos perpetrarem um determinado comportamento, mais forte e intensa se torna a ressonância de seu campo, fazendo com que mais e mais indivíduos entrem em sintonia com o mesmo, e assim se comportem da

\footnotetext{
${ }^{7}$ Fenômeno de comunicação de Campos Morfogenéticos
} 
mesma forma. Para o biólogo, o que orientaria o comportamento de uma mariposa, por exemplo, seria o campo morfogenético responsável pela sua reprodução. Apesar de só se realizar uma única vez em toda a sua vida, isto já é suficiente, pois o que importa não é a quantidade de vezes que o comportamento se repete, mas sim o fato de o mesmo estar em ressonância com o campo que dirige tal ação. Tal campo teria surgido em tempos imemoriais, e persistido através do tempo e do espaço graças à Ressonância Mórfica.

- A geometria fractal desenvolveu-se a partir de estudos de Benoit Mandelbrot sobre complexidade, nas décadas de 1960 e 1970. Mandelbrot cunhou o termo "fractal" com base na palavra latina fractus ["quebrado"], para ressaltar a natureza fragmentada e irregular dessas formas.

- Os fractais têm auto-similaridade-isto é, um aspecto semelhante sob qualquer ampliação. Uma pequena parte da estrutura é bastante semelhante ao todo.

- Existem dois tipos de auto-similaridade: a exata e a estatística. Aárvore artificial (série à esquerda) apresenta uma repetição exata dos padrões em diferentes ampliações. No caso da árvore real [à direita], os padrões não se repetem com exatidão; em vez disso, as qualidades estatísticas dos padrões é que se repetem. A maioria dos padrões existentes na natureza obedece à auto-similaridade estatística, e o mesmo se aplica às pinturas de Pollock.

- Os fractais são caracterizados por sua "dimensão", ou complexidade. A dimensão não é um número inteiro, como as dimensões 1,2 e 3 da geometria euclidiana. Em vez disso, as dimensões fractais são fracionárias; por exemplo: uma linha fractal possui uma dimensão entre 1 e 2 .
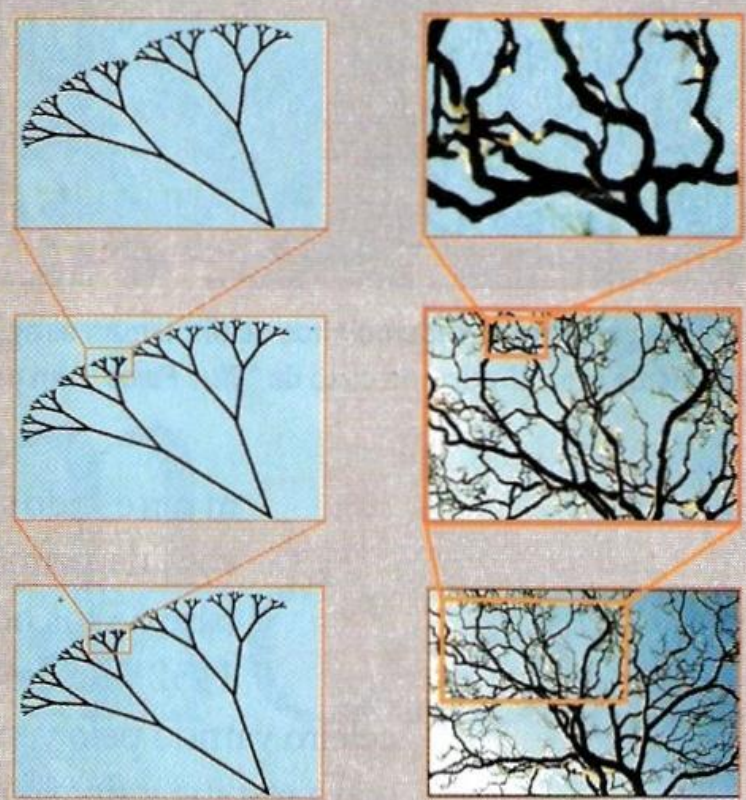

ÁRVORE ARTIFICIAL Auto-Similaridade Exata

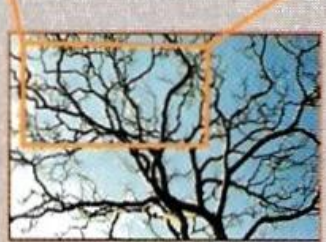

ÁRVORE REAL Auto-Similaridade Estatística

A Auto Similaridade

A idéia de "caos" tem se modificado com o passar das épocas, na Mitologia grega: O seu nome deriva do verbo grego chao, que significa "estar aberto". Assim, o caos significa, literalmente, a vida infinita, anterior à criação e contendo em si todas as possibilidades. Entretanto, por confusão com o verbo chéo (derramar), pode-se igualmente considerar o Caos como sendo a matéria inerte, derramada no espaço. Caos era um estado primordial do mundo, uma 
matéria vaga, indefinível, indescritível, e ao mesmo tempo uma divindade capaz de fecundar.

Temos trabalhado com a idéia de que os Sistemas caóticos ${ }^{8}$, ainda que com esses elementos de imprevisibilidade, criatividade, mutabilidade entre outros, pelos quais podemos chegar a essas narrativas casuais que são efêmeras, não são de fato tão incompreensíveis assim. Quando nos damos conta dessas propriedades físico-matemáticas comuns e percebemos que existem padrões, por exemplo, quando numa marcha aleatória suficientemente longa encontramos uma estrutura fractal, ou nos deparamos com estruturas auto-similares, começamos a compreender que esse código pode nos auxiliar em nossa vivência, na experiência que temos com o mundo, nos garantindo uma visão um pouco menos limitada do universo.

Certamente a lógica, a matemática, a razão, não são as únicas maneiras de se lidar com essa linguagem. Sabemos que Jackson Pollock é um artista de uma época que precedeu em mais de 20 anos o desenvolvimento da Teoria do Caos e que seu interesse na pintura era com os ritmos da natureza. Embora não tenha sido uma questão para ele e o tenha feito involuntariamente, e principalmente devido sua maneira diferenciada de pintar - com gestos espontâneos junto aos respingos de tinta - identificamos constantemente em sua pintura os padrões geométricos fractais

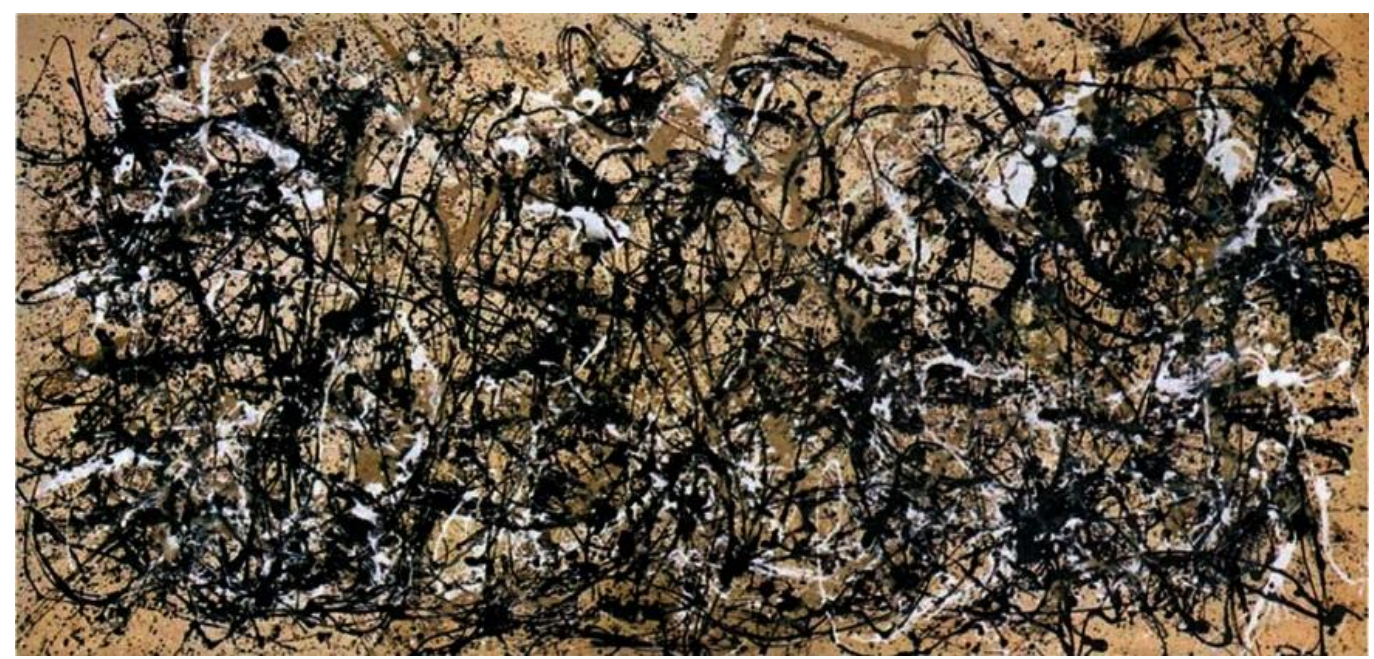

Pollock - Autumn Rhythm

\footnotetext{
${ }^{8}$ Seriam os mecanismos usados para descrever a Teoria do Caos. Bons exemplos de sistemas caóticos são o crescimento de lavouras e a formação de tempestades, onde qualquer pequena alteração, direção, velocidade de ventos por exemplo, pode provocar grandes mudanças num espaço de tempo maior.
} 
Sabemos que Mondrian buscava o que existia de constante nos seres. Afirmava que cada coisa possui uma essência que está por trás de sua aparência e as coisas, em sua essência, estariam em harmonia com o universo. O papel do artista, para ele, seria revelar essa essência oculta e essa harmonia universal.

A manifestação do Caos, a percepção, se dá em função do tempo, na passagem deste e em como o tempo é percebido pelo interator ou espectador de um evento caótico, ou seja, sem o passar do tempo não se teria percepção da manifestação do caótico. Estes momentos são períodos muito preciosos, momentos em que podemos decidir entrar neste mundo do caos, como se estivéssemos dando um passeio sem uma rota estabelecida. São momentos que nos dão a impressão de sairmos do tempo mecânico e programado, como o de um "tic-tac" de um relógio.

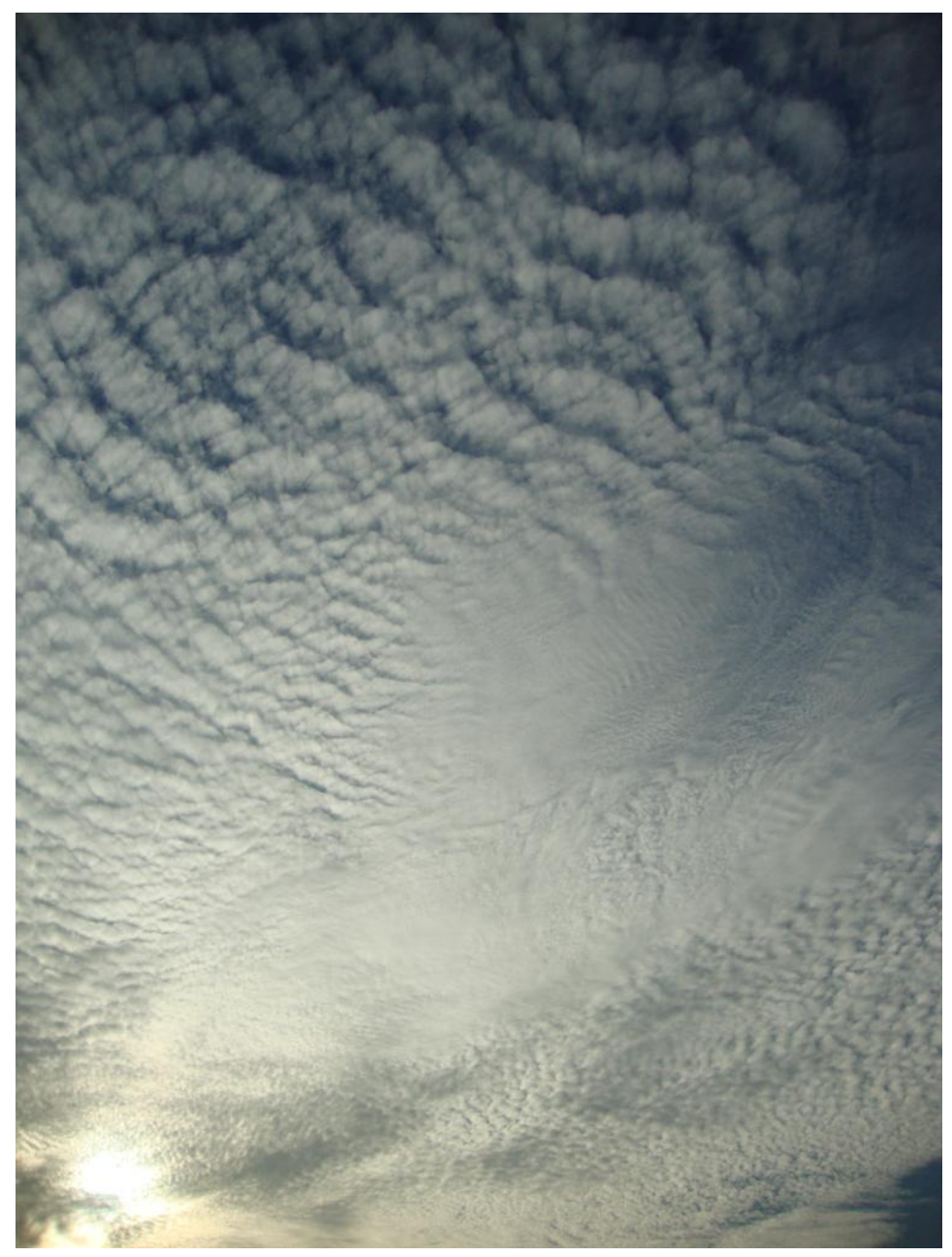

As nuvens e a sua geometria fractal 


\section{II.NARRATIVAS CAÓTICAS}

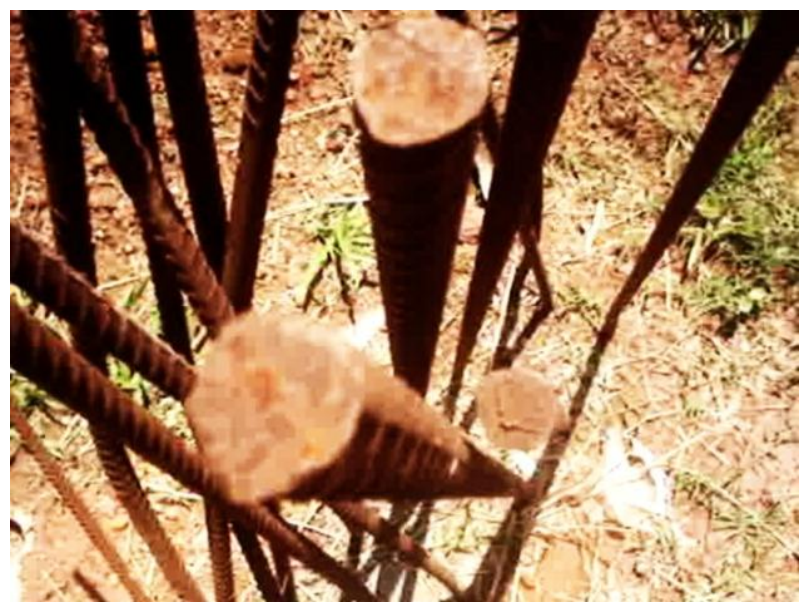

Canteiro das obras - 2009

\subsection{Vaesmo}

Vaesmo é uma instalação computacional interativa. Trata-se de um conjunto de programas de computador nos quais áudios e vídeos podem ser executados e sintetizados em tempo real.

A obra foi desenvolvida em softwares livres, seu código é aberto a modificações podendo ser copiado e distribuído a todos. A ferramenta utilizada para programação foi o software Pure Data e para o reconhecimento dos símbolos o programa reacTIVison.

A edição de som e vídeo proposta ao público é possibilitada pelo uso de uma interface diferenciada. Os interatores movem objetos sobre uma mesa de vidro, nestes objetos estão colados símbolos que são reconhecidos pelo computador através de uma câmera de vídeo. Os diferentes símbolos são associados a dois tipos principais de funções: 1) dar início a exibição de um vídeo e seu respectivo áudio. 2) aplicar um efeito ao vídeo ou ao som.

É fundamental lembrar que muitos objetos podem ser reconhecidos simultaneamente, o que permite que se executem vários vídeos e sons, aplique-se efeitos a todos eles como: colorização, mescla, negativo da imagem, eco aos sons, entre outros. Cada objeto acrescentado ao sistema o transforma como um todo.

O programa possui uma pequena biblioteca de vídeos que são de autoria própria, fazem parte de uma pesquisa artística que tenta relacionar 
performance visual e sonora, e Teoria do Caos. Os vídeos são registros de performances nas quais foram executadas musicas com instrumentos ou meios não convencionais. Câmeras presas dentro de roda de bicicleta, percussão ou mesmo captando sons executados nos vergalhões de um canteiro de obras.

A vídeoarte e composição musical se concretizam durante a execução dos interatores, que escolhem ao acaso que vídeos e efeitos utilizarem. A movimentação dos objetos sobre o vidro também é reconhecida pelo computador, possibilitando uma regulação dos efeitos, aumentando com isso as possibilidades de composição. O resultado da interação é projetado e enviado a caixas de som em tempo real.

O usuário deste contexto realiza seus percursos, escolhe seu ritmo, suas direções de ir e vir e estabelece suas referências e significados próprios. $\mathrm{Na}$ medida em que o conteúdo é lido pelos participantes, as imagens dividem-se sucessivamente entre estados não formalizados e atualizados, fazendo de cada leitura um acontecimento singular e único. (PARAGUAI, 2008, 28)

A projeção é acionada, quando se coloca o objeto sobre a superfície da interface, ali permanecem em loop enquanto o símbolo colado ao objeto é captado pelo sistema. O loop do vídeo simula uma temporalidade contínua, porém o tempo de absorção da obra é variável, vai de acordo com a velocidade em que os interatores compõem com os vídeos.

Os vídeos propõem narrativas nas quais o espectador se depara com fenômenos ou ritmos da natureza que apresentam a idéia da não existência de acaso e sim da existência de uma lógica, lei ou linguagem do caos. Dessa forma a fruição se dá através de um código ou lógica caótica que acabam por induzir de certa maneira um estranhamento ao espectador pela não correspondência desse código com a matemática tradicional. Foram produzidos sete vídeos para a obra Vesmo: Torneira Gotejante I, II e III, Isto é "Cascata", "Rolê" e Canteiro das Obras I e II.

Nos vídeos Torneira Gotejante I, I/ e III, o caráter experimental aparece no ato de gravação dos vídeos, tendem ao registro de performances musicais, funcionando também como registros de eventos naturais caóticos. Em contrapartida, o vídeo também dependeu da experiência de controlar o fluxo das gotas d'água pela torneira, de compor esteticamente os objetos e 
enquadramento da câmera. Acabam por gerar um campo (que tende para o) simbólico.

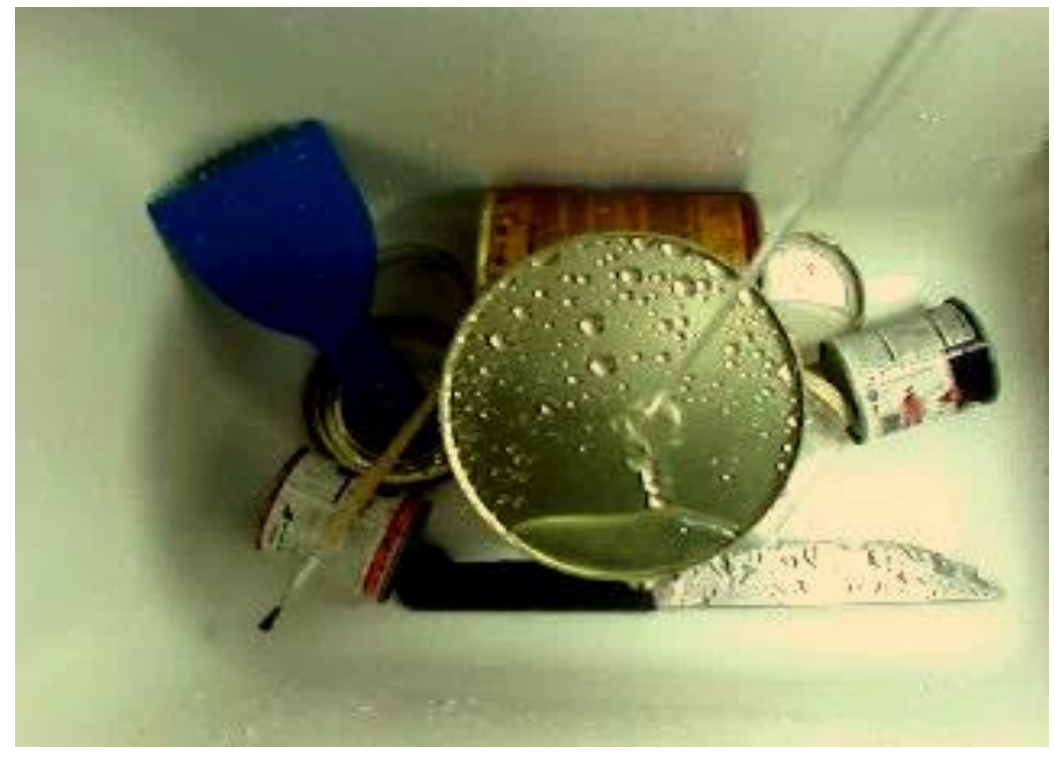

Torneira Gotejante I - 2008

$\mathrm{Na}$ primeira experiência de vídeo feita com o sistema da torneira gotejante, vemos pincéis, latas de tinta, espátula são objetos que vemos com freqüência em ateliês de pintura. No segundo vídeo meu corpo em conjunto com o ambiente se dissolve tornando-se um atrator caótico que interage com a torneira. Esses elementos icônicos, como as gotas em probabilidades viciadas que se transformam em jorro, e o som que tem o seu ritmo alterado de acordo com o tempo de exposição ao atrator indica que a narrativa caótica se manifesta juntamente com a passagem do tempo.

O som da gota nas superfícies exploradas e o seu aspecto visual no momento de colisão com o fundo é o elemento chave para se compreender como Torneira Gotejante cria um conflito em relação ao que tendemos denominar como formas casuais, por exemplo; o som das gotas provocam os sentidos de uma forma a despertar a percepção de algo aleatório - e do mesmo modo as formas únicas que surgem com água no momento de colisão - tanto em um exemplo quanto no outro os intervalos dos ritmos nunca são iguais, porém ainda assim podemos perceber uma certa similaridade entre os eventos no decorrer do vídeo. Este perceber de semelhanças sonoras e visuais é que nos acostuma com esse código ou lógica natural que matemática tem apresentado em seus modelos do Caos. 


\section{Caixa de Dados}

Caixa de Dados, produzida em meados de 2009, foi fundamental no desenvolvimento da pesquisa. A animação feita com programação multimídia, cria composições usando Cubos 3D. Os cubos se movimentam através do sorteio de coordenadas $X, Y$ e Z . Dois sorteios diferentes de coordenadas $X, Y$ e Z são feitos para o movimento de cada cubo: um de translação e outro de rotação.

A textura dos cubos foi feita a partir de uma fotografia de vários dados de seis lados, os pixels que compõem esta imagem são reordenados simulando um caleidoscópio.

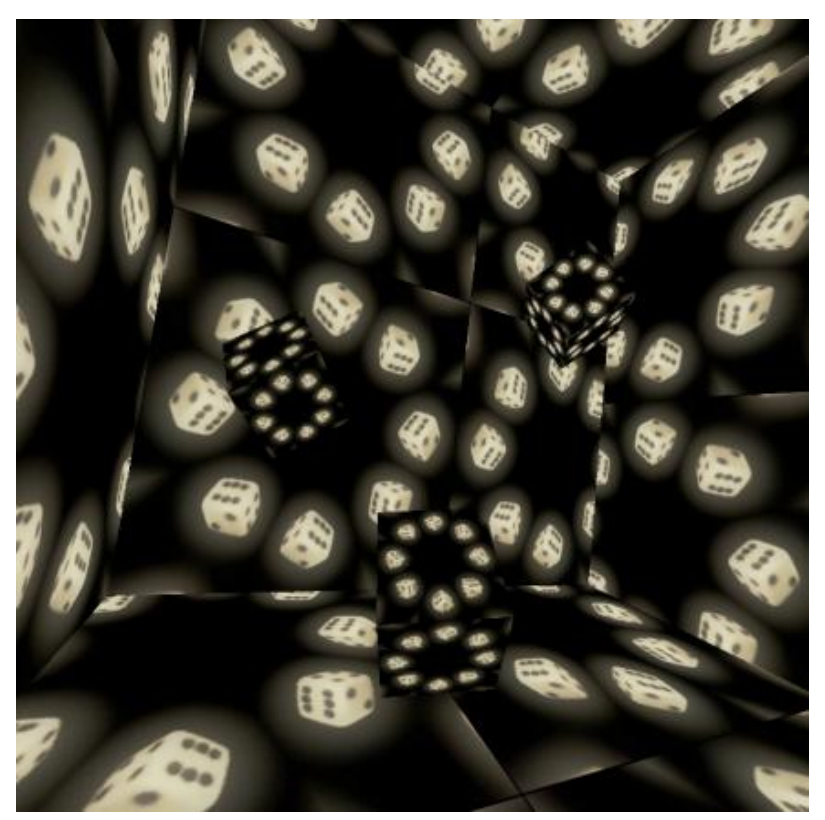

Caixa de Dados - 2009

Este caleidoscópio, designado para textura dos cubos, também foi programado para se modificar por sorteio de variáveis. O programa escolhe randomicamente o número de "espelhos" e a forma como a fotografia deve se mover. Move a textura diagonalmente, verticalmente, horizontalmente e gira também no sentido horário e anti-horário.

Como resultado da experiência, Caixa de Dados nos dá a impressão de que os dados se movem tal qual como se estivessem a sacudir dentro de uma caixa tratando-se na verdade de uma animação com movimentos randômicos. 
O áudio, também programado randomicamente, tende a nos transmitir a metáfora entre dados de jogo e dados de computador. As combinações dinâmicas e imprevisíveis em tempo real, entre áudio e imagem, tanto dos samplers $^{9}$ disparados aleatoriamente como das texturas fractais e dos movimentos dos dados, trazem a possibilidade de composições que se reordenam "infinitamente".

Se vocês considerarem o sistema caótico, tal como resulta da análise dos resultados de uma triagem aleatória do jogo dos dados, verão surgir configurações complexas as mais diversas: vocês têm sempre a possibilidade de ver aparecer as figuras as mais raras. A Raridade informacional habita então o caos, do mesmo modo que a desordem.(...) o caos é essencialmente dinâmico, é composto de entidades animadas com velocidade infinita, que ora as precipita em um estado de dispersão absoluta, ora reconstitui, a partir delas, composições hipercomplexas ${ }^{10}$. (GUATTARI, 1992: 78)

Caixa de dados sustenta a relação entre o acaso $^{11}$ e o pré-estabelecido através da dualidade entre as formas fixas e as casuais que estão em constante diálogo. Com relação ao acaso temos as freqüências sonoras, a mudança de timbres através do processo síntese ring modulator ${ }^{12}$, a síntese da imagem e movimentação dos objetos; o pré-estabelecido são os vinte e um fragmentos de áudio pré-gravados com sons de dados lançados em diversas superfícies, e fotografias de dados de jogo em tamanhos e ângulos diversos.

\footnotetext{
${ }^{9}$ Fragmentos de áudio pré-gravados.

${ }^{10} \mathrm{O}$ caos, ao invés de ser um fator de dissolução absoluta da complexidade, torna-se o portador virtual de uma complexidade infinita. (GUATARRI, 1992: 78)

${ }^{11}$ Podem-se distinguir três conceitos desse termo que se entrecruzaram na história da filosofia. $1^{\circ} \mathrm{o}$ conceito subjetivista, que atribui a imprevisibilidade e a indeterminação do evento casual à ignorância ou à confusão do homem. $2^{\circ} \mathrm{o}$ conceito objetivista, que atribui o evento casual à mistura e à interseção das causas. $3^{\circ}$ a interpretação moderna, segundo a qual o acaso é a insuficiência de probabilidades na previsão. Este último conceito é o mais geral e o menos metafísico.

${ }^{12}$ Processo de síntese sonora por modulação de amplitude da onda.
} 


\section{Considerações Finais}

Tanto Vaesmo como Caixa de Dados são propostas de mostrar a imagem em dinâmicas não lineares, mexem com a seqüencialidade de acontecimentos, tornando-os flexíveis em termos de percepção e reorganização, ora com a aceleração ora com desaceleração do tempo de leitura. propondo, na maneira do possível, a idéia de que a linguagem do Caos pode estar ligada à idéia de narrativa de marcha aleatória.

A ferramenta VijhoDrão não termina com o fim do projeto Vaesmo, é uma das nossas primeiras experiências de instalação multimídia interativa com o uso desta interface. Visamos dar continuidade ao seu desenvolvimento, buscando parcerias, para sua construção, reflexão a respeito do meio de expressão VJ, linguagem da performance audiovisual, acessibilidade e democratização dos meios de produção cultural.

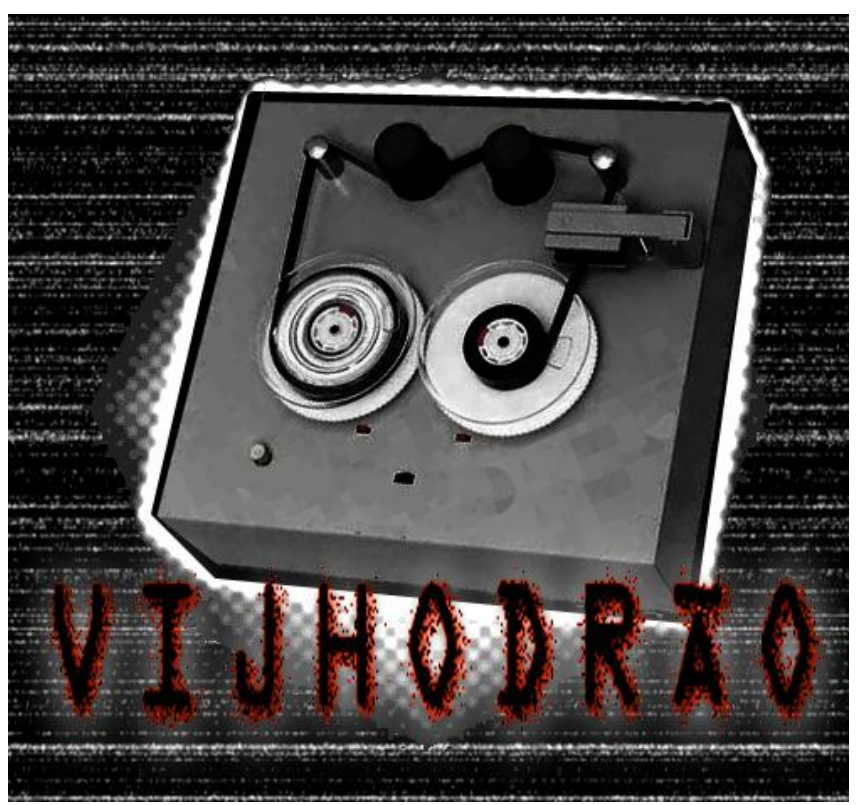

Ícone prévio do programa VijhoDrão 


\section{REFERENCIAS BIBLIOGRÁFICAS}

Livros, catálogos e artigos

ABRAHAM, Ralph; Rupert Sheldrake e Terence Mckenna. Caos, Criatividade e o Retorno do Sagrado: Triálogos nas fronteiras do Ocidente. Trad. EICHENBERG, Newton. Ed Pensamento. São Paulo, SP. 1992.

ANTUNES, Jorge. A Correspondência entre os Sons e as Cores. Brasília: Thesaurus. 1982.

ARANTES, Priscila. Arte e mídia: perspectivas da estética digital. Ed Senac. São Paulo, SP. 2005

BASBAUM, Sérgio. Sinestesia - Arte e tecnologia, fundamentos da cromossonia. São Paulo:Annablume/FAPESP. 2002

COSTA , Mario. O Sublime Tecnológico. São Paulo: Experimento, 1995.

GUATTARI, FELIX, Caosmose:Um Novo Paradigma Estético. Trad. Ana Lúcia de Oliveira

MACHADO, Arlindo. Hipermídia: o labirinto como metáfora, in DOMINGUES, Diana (org.), A arte no século XXI - a humanização das tecnologias. São Paulo: Unesp, pp. 144-145, 1997.

- Máquina e Imaginário: o desafio das poéticas tecnológicas. São Paulo, Edusp, 1993.

PARENTE, André. Imagem-Máquina: a era das tecnologias do virtual. Trad. Rogério Luz et alii. Ed. 34, Rio de Janeiro, 1993.

PRIGOGINE, llya. As leis do Caos. São Paulo: Unesp, 2000.

VENTURELLI, Suzete. Arte: espaço, tempo, imagem. Brasília: UnB, 2004.

Softwares:

PUCKETTE, Miller. PureData (PD) versão: extended 0.41.4, 2009

http://www.puredata.info/

KALTENBRUNNER, Martin e Ross Bencina. ReactVision, versão: 1.4, 2005 
http://reactivision.sourceforge.net/

Web Sites:

MUTSCHLER, Hans - Dieter. Introdução à filosofia da natureza. disponível em:

http://books.google.com.br/books?id=e8NlgoXY cC\&pg=PA153\&dq=teoria + do + Caos\&ei=23DpSPnQMIGSyAS0xc iJAQ\&sig=ACfU3U0syzy-dJcNu3ZRv3iX7jKvyVIW6A\#PPP1,M1 .Acesso em $17 / 11 / 2011$

PARAGUAI, Luisa. Narrativas imagéticas na Web: leituras e construções hipertextuais. Doc On-line, n.05, Dezembro 2008, www.doc.ubi.pt, pp. 24-35. Disponível em: http://www.doc.ubi.pt/05/artigo luisa paraguai.pdf. Acesso 17/01/2011 SOKAL, Alan D. e Jean Bricmont. Imposturas Intelectuais: O abuso da ciência pelos filósofos pós-modernos. Disponível em:

http://books.google.com.br/books?id=lbwLd1RY2wkC\&pg=PA144\&dq=te oria + do + Caos\&ei=23DpSPnQMIGSyAS0xciJAQ\&sig=ACfU3U1f FiU81c YXRX WtZ-AldzbBqO5Q\#PPA144,M1. Acesso em 17/01/2011 